\title{
Tax Capacity and Growth in the Asia-Pacific Region
}

April 2019

\begin{abstract}
In this paper, we estimate short- and long-term tax buoyancy for 30 Asian-Pacific countries during 1980-2017 using recent panel techniques. Using Mean Group estimators, we found that the shortrun buoyancy is statistically not different from one, while the long-run buoyancy is statistically larger than one. In 11 out of 30 countries, growth has improved fiscal sustainability over time, while in only 4 out of 30 countries the tax system has acted as a good automatic stabilizer. Results are robust to the estimation with alternative estimators, the inclusion of inflation and tax rates. We uncovered that buoyancies increased in magnitude and significance over time. Lastly, resorting to nonlinear estimations of short-run buoyancies contingent on the phase of the business cycle, we find that buoyancy is generally larger during recessions.
\end{abstract}

JEL: E62, H21, H29, H68

Keywords: tax elasticity; business cycle; error correction model; filtering; pooled mean group; nonlinear models 


\section{Introduction}

The Addis Ababa Action Agenda in 2015 set up seven key actions one of which was to mobilize more revenues domestically. The need for additional resources is paramount, particularly in developing and emerging countries, to finance the Sustainable Development Goals by 2030. The 2019 UN's Financing for Sustainable Development Report shows "that enhancing domestic revenues through tax reform and reducing illicit financial flows will provide much needed fiscal space for governments to fund their development programs". Indeed, any tax system's main function is to bring in sufficient revenue to meet growing public sector requirements and over time, tax systems across different countries have been revamped, restructured and reformed with the objective of maximizing tax revenues.

To determine if a country has made efforts at increasing tax revenue over a period, one needs to introduce a critical ingredient of a tax system, the so-called tax buoyancy (Asher, 1989). ${ }^{1}$ The buoyancy degree of a tax system reveals the total response of tax revenue to changes in national income as well as "discretionary" (or non-automatic) changes in tax policies. Despite being closely related to buoyancy, the concept of elasticity of the tax system measures the responsiveness of tax revenue to changes in national income resulting from "discretionary" modifications in the tax structure, that is, keeping all other parameters (including tax legislation) constant (Skeete et al., 2003). When the elasticity of revenue sources is low (due to e.g. low base, evasion or avoidance), governments raise additional resources through discretionary measures. ${ }^{2}$ Hence, tax revenue growth comes through high buoyancy rather than through elasticity. ${ }^{3}$

A large buoyancy is a desirable feature of a tax system: in addition to augmenting the revenue productivity, it fosters overall fiscal operations by mitigating undesired cyclical movements. ${ }^{4}$

\footnotetext{
${ }^{1}$ Two of the first set of papers making an attempt to measure the tax effort in developing countries was done by Lotz and Morss (1967) and subsequently by Chelliah et al (1975).

${ }^{2}$ Lacking information on discretionary measures for the panel of Asian countries studied in this paper and under the assumption that the effects of these changes on revenues cancel each other out over time, then tax buoyancy is estimated via a regression of the log of tax revenue on the log of GDP. This is the approach followed in this paper.

${ }^{3}$ In some sense, elasticity is more appropriate to use to estimate the impact of, say, an unexpected decline in the tax base (owing, for example, to a natural disaster) on revenues, or the increase in, say, personal income tax revenues over time if brackets are not adjusted and deductions allowances remain the same. Buoyancy on the other hand, more appropriately measures past revenue developments or the combined effects of a package of reforms.

${ }^{4}$ A buoyancy of one would imply that an extra percent of GDP would increase tax revenue also by one percent, thus leaving the tax-to-GDP ratio unchanged. A tax buoyancy exceeding one, however would increase tax revenue by more than GDP and potentially lead to reductions in the deficit ratio. If buoyancy is low, discretionary changes may make up for it, but it can be lagged and disproportionally high (Blanchard et al., 2010).
} 
Hence, the assessment of tax buoyancy is an important part of a macro model of any economy. Moreover, as in many other emerging and developing countries, the public finance sector in several Asian countries is the focal point of many of the conflicts and challenges posed by economic development. The domestic resource mobilization imperative to improve the redistributive, allocative and stabilization functions of the government (Musgrave, 1969) is greatly compromised by these challenges. Several efforts aimed at obtaining optimal fiscal policies with emphasis on the role of taxation, as an instrument of economic development, have been implemented over time (Ndikumana and Abderrahim, 2010).

A detailed study of tax buoyancy in Asia is relevant for multiple reasons: i) for purposes related to revenue forecasting; ii) to analyze the responsiveness and stabilizing role of tax systems; iii) and to examine the progressivity of a tax system to address equity considerations. In other words, by assessing country-specific degrees of tax buoyancy, one can ascertain if the government is keeping track on tax mobilization with economic activity. Moreover, estimation of individual tax buoyancies helps shedding light on weaknesses and strengths of the system and guides fiscal authorities in identifying those taxes which are income elastic or not and, therefore, aim at directing their efforts at the more elastic ones to raise overall tax revenue.

Tax buoyancy can also differ between the short- and the long-run. The former is linked to the stabilization role of fiscal policy. In fact, if the short-run tax buoyancy is larger than one, then the tax system can be considered as a good automatic stabilizer, by smoothing economic activity directly. ${ }^{5}$ Contrarily, long-run buoyancy is a steady-state concept and it is of relevance to assess the effect of economic growth on long-term fiscal sustainability. ${ }^{6}$ This is particularly relevant in the context of the recent Global Financial Crisis which led governments around the world to make use of fiscal policy to counter the fall in aggregate demand with the undesirable consequence of growing public indebtedness and endangering the sustainability of public finances. In the face of sustainability problems and with low tax elasticities/buoyancies, engaging in such demandboosting policy stance is not advisable. Today's need for government's greater (fiscal) accountability, discipline and effectiveness, has led many practioneers and academics to revive the

\footnotetext{
${ }^{5}$ Fiscal stabilizers reduce output fluctuations because some components of fiscal accounts react automatically to the cycle, increasing public deficits in recessions and decreasing them in expansions. For a recent contribution on the stabilization role of fiscal policy see Furceri and Jalles (2018).

${ }^{6}$ Sustainable fiscal policies are those that can be continued indefinitely without any change in the policy stance and when the intertemporal government budget constraint holds in present value terms.
} 
debate around the best policy options at a time a budget is designed. In normal times, fiscal discussions are centered around which taxes and/or spending items to decrease and/or increase (see e.g. Jha et al., 2014). In this context, it is paramount to understand how different taxes behave with economic activity, particularly around business cycle's turning points.

This paper contributes to the literature by being the first to estimate both short and long-run tax revenue buoyancies for 30 Asian-Pacific countries over a relatively long-time period (1980-2017) by means of Mean and Pooled Mean Group estimators. Not only are short and long-run tax buoyancy estimates provided for total tax revenue but also for four tax categories, namely personal income tax, corporate income tax, taxes on goods and services and trade taxes which, in 2017, accounted for more than 80 percent of tax revenues in these countries. In addition, this paper studies how business cycle's turning points impact buoyancy estimates. These 30 Asian-Pacific countries have, on average, made progress in mobilizing more taxes as its ratio to GDP has been rising since the early 2000's, despite the fall after the Global Financial Crises in the more recent period (Figure 1, panel a). The growth rate of nominal tax revenues and nominal GDP has been highly correlated in this group of countries (correlation coefficient of 85 percent), sometimes higher, sometimes lower, making it difficult to certainly claim that average tax buoyancy has been greater than one over this period (Figure 1, panel b). ${ }^{7}$

Figure 1. Tax Revenues (percent of GDP) (panel a) and Growth in Nominal GDP and
Tax Revenue (percent) (panel b) in Asian-Pacific Countries, 1980-2017

a)

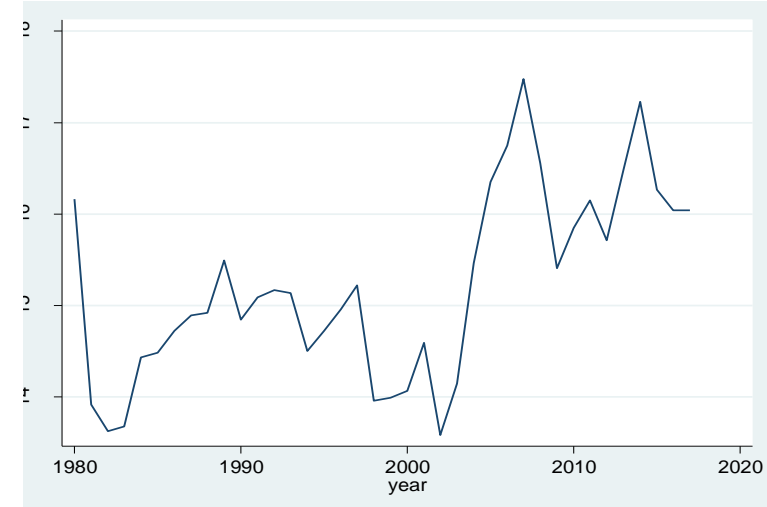

b)

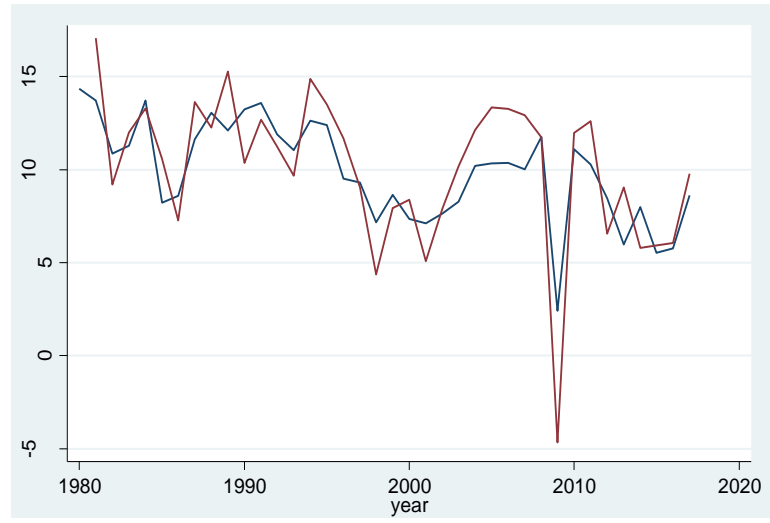

Note: In panel a) blue line denotes tax revenues in percent of GDP. In panel b) blue line denotes the growth rate of nominal tax revenue; red line denotes the growth rate of nominal GDP. Source: author's calculations.

\footnotetext{
${ }^{7}$ Nominal GDP grew on average 1.6 percent per year while nominal tax revenues grew on average 1.3 percent per year over the period 1980-2017.
} 
On average, in this group of countries tax revenues have been increasing over the last decades particularly driven by corporate income tax and taxes on goods and services. Using Mean Group estimators, we found that the short-run buoyancy is statistically not different from one, while the long-run buoyancy is statistically larger than one (driven by a high corporate income tax buoyancy). In 11 out of 30 countries, growth has improved fiscal sustainability over time. In only 4 out of 30 countries the tax system has acted as a good automatic stabilizer as evidenced by shortrun buoyancies statistically larger than one. Results are robust to the estimation with alternative estimators, the inclusion of inflation and tax rates. We also uncovered that buoyancies increased in magnitude and significance over time. Finally, resorting to nonlinear estimations of short-run buoyancies contingent on the phase of the business cycle, we find that buoyancy is generally larger during recessions than in normal times. One key novelty in this last point is the manner in which we identify recessions based on a newly computed measure of the output gap for these countries that relied on the recent filtering technique suggested by Hamilton (2018).

The remainder of the paper is organized as follows. Section 2 reviews the literature. Section 3 develops the conceptual and econometric approach. Section 4 presents the data. Section 5 discusses our empirical results. The last section concludes.

\section{Literature Review}

Estimates of revenues elasticities abound in the literature, both for groups of countries (mostly advanced due to data availability and quality issues) and for individual countries.

Combining developed and developing countries, Choudhry (1979) was one of the first authors to estimate the elasticity of tax revenue. He focused on the United States, United Kingdom, Malaysia and Kenya. The overall elasticities were found to be 1.04 and 1.24 for the United States and United Kingdom, respectively. Malaysia and Kenya had slightly higher elasticities of 1.57 and

\subsection{2 respectively.}

Later, while Bouthevillan et al. (2001) inspected euro area countries, Giorno et al. (1995) and Girouard and Andre (2005) estimated revenue elasticities for OECD countries. More recently, Belinga et al. (2014) looked at short and long-run coefficients for a panel of OECD countries between 1965-2012. The authors found that for aggregate tax revenues, short-run tax buoyancy did not significantly differ from one in most countries; however, it increased since the 1980s suggesting that tax systems have gradually become better automatic stabilizers. Mourre and 
Princen (2015) provided panel estimations of dynamic tax elasticities for the EU. Deli et al. (2018) found that tax revenue estimates were not different from unity while personal income tax buoyancies were smaller than one in a sample of 25 OECD countries between 1965-2015. A paper by Lagravinese et al. (2020) finds both short- and long-run buoyancy in OECD countries to be less than one - a result that is starkly different from earlier studies.

For non-OECD countries, most studies cover the developing regions of Africa and Asia and perform, generally, single country analysis. Focused in Africa examples include Osoro and Leuthold (1994) and Twerefou et al. (2010). Osoro (1995) established that the elasticity of the overall tax system in Tanzania declined from 0.85 in 1970 to 0.78 in 1980 attributed to an exchange rate depreciation. A similar finding was found by Chipeta (1998) for the case of Nigeria. Some other authors looked at the impact of specific tax reforms on tax elasticity. For instance, Ayoki et al. (2005) found that reforms in Malawi positively impacted directed taxes as evidenced by an increase in the tax-to-income elasticity index from 0.71 to 1.08. More recently, Bruckner (2011) estimated the tax revenue of several sub-Saharan African countries using a novel instrumental variable approach. He suggested the existence of high tax revenue elasticities in the region. In contrast, Twerefou et al. (2012) showed that the overall tax and individual tax categories in Ghana were not buoyant in the short-run with the exception of personal income tax. Bekoe, Danquah and Senahey (2016) also focusing on Ghana between 1970-2013 showed that tax reforms in the country positive influenced the overall tax structure as evidenced by more than unit buoyancies and elasticities.

Focusing specifically in Asia, Thac and Lim (1984) examined Papua New Guinea's tax performance and estimated both tax elasticities and tax buoyancies for different tax categories between 1965-1977. They found that for total tax revenue the elasticity coefficient was estimated to be 1.32 while the buoyancy coefficient was estimated to be 1.85 . Shome (1988) discussed the impediments to an automatic response of tax revenue to economic growth by focusing on developing Asian countries. He then argued that there was some built-in inflexibility in raising the elasticity of a typical Asian tax system. Bilquees (2004) studied the elasticity and buoyancy of the tax system in Pakistan using the Divisia Index method over the 1974-2004 period. He showed a total tax buoyancy and elasticity after the reform as 0.92 and 0.88 , respectively and concluded that the overall adoption of discretionary tax measures has been significant in generating more revenues to the country. In the context of the structural changes that took place in Nepal in recent years, 
Timsina (2007) applied time series techniques to reveal that Nepal's tax system was inelastic (less than unity) between 1975-2005. However, buoyancy was higher than one reflecting that the bulk of revenue collection emanated from discretionary changes in the tax policy rather than from automatic responses. Jayawickrama (2008) focused on the Sri Lanka case since the 1990s to concluded that both the low buoyancy of corporate income tax and the susceptibility of goods and services tax to unexpected non-structural shocks were the main causes of the declining revenue to GDP ratio. Yousuf and Huq (2012) studied elasticity and buoyancy of major tax categories in Bangladesh are found that most of the growth in revenues was achieved due to discretionary changes instead of automatic growth.

For this review it is clear that a panel inspection of the Asian region that includes an analysis of both short and long-run buoyancies is currently absent which is the gap this paper aims to bridge. Moreover, by focusing on the Asian-Pacific region we are able to include some islands and smaller states commonly ignored in empirical studies.

\section{Conceptual and Empirical Methodology}

The buoyancy of a tax system is measured by the proportional change in total tax revenue with respect to the proportional change in national income and it can be expressed as:

$$
b_{T, Y}=\frac{\partial T}{\partial Y} * \frac{Y}{T}
$$

where $\mathrm{T}$ is total tax revenue, $\mathrm{Y}$ is GDP and $\partial$ denotes continuous changes in the variables.

The buoyancy of a tax can be obtained by a linear regression equation of the form:

$$
T=\alpha+\beta Y+\varepsilon
$$

where $\alpha$ is a constant, $\beta$ is the marginal rate of taxation, $\varepsilon$ is an error term and the rest of variables are defined as before. Since $\partial T / \partial Y=\beta$, it follows that buoyancy (or elasticity) $B_{T, Y}=\beta(Y / T)$. This method involves the estimation of $\beta$ and calculation of the term (Y/T) by averaging $\mathrm{Y}$ and $\mathrm{T}$ over the sample period in order to eliminate cyclical influences. An alternative method, which is followed in this study, is to express equation (2) in exponential form as:

$$
T=\alpha Y^{\beta} \varepsilon
$$

Log linearizing equation (3) gives us the following: 


$$
\log T=\log \alpha+\beta \log Y+\varepsilon
$$

In this case, the estimate of $\beta$ corresponds to tax buoyancy.

An important dimension when referring to buoyancy is time. Over the short run, buoyancies can be different from one, and they can be different across revenue items. ${ }^{8}$ However, over the long run it is expected that buoyancy be equal to one. If not, at least on theoretical grounds, there would come a point where revenues exceed 100 percent of their base. Even though the time dimension of the dataset allows us to run individual regressions, we rather fully exploit the panel dimension for three main reasons: first, it enables to by-pass the difficulty related to short-spanned time series; second, tests are more powerful than the conventional ones: third, cross-section information reduces the probability of a spurious regression (Barnerjee, 1999). ${ }^{9}$

The time-series properties of our data play an important role. ${ }^{10} \mathrm{We}$ conjecture that the potential bias resulting from estimating buoyancy coefficients using fixed-effects models is the result of nonstationary errors, which are introduced into the estimating equation by the imposition of parameter homogeneity. Hence, careful modelling of short-run dynamics requires a slightly different econometric approach, relative to equation (4) derived in the previous section. Consider the equation:

$$
\Delta \ln y_{i t}=\beta \Delta \ln x_{i t}+\mu_{i}+\eta_{t}+\varepsilon_{i t}, i=1,2, \ldots, N ; t=1,2, \ldots, T
$$

where $\beta$ is an unknown (buoyancy) parameter to be estimated, $y_{i t}$ denote the tax revenue variable (in nominal terms) and $x_{i t}$ denotes nominal GDP. $\mu_{i}, \eta_{t}$ are time and country fixed effects, respectively. $\varepsilon_{i t}$ is the model specific error term satisfying the standard assumptions. We then assume that (5) represents the equilibrium which holds in the long-run, but that the dependent variable may deviate from its path in the short-run. There are often good reasons to expect the long-run equilibrium relationships between variables to be similar across groups of countries, due

\footnotetext{
${ }^{8}$ For example, adjustments to revenue brackets for the computation of personal income taxes may lag household income development. Indexation of deduction allowances may be different from inflation. These factors would explain a strong response of revenues to economic development over the short-run.

${ }^{9}$ Recall that t-ratios are invalid for the estimations if error terms are nonstationary.

${ }^{10}$ Results of first (Im et al., 1997) and second generation (Pesaran, 2007) panel integration tests suggest that we cannot reject that the null hypothesis of non-stationarity (these are available from the authors upon request).
} 
e.g. to budget constraints, fiscal rules or even common technologies influencing them in a similar way. We assume that the long-run relationship is composed of a country-specific level and a set of common factors with country-specific factor loadings. The parameters of (5) can be obtained via more recent panel data methods. Here, we consider the Mean Group (MG) estimator (Pesaran and Smith, 1995) and the Pooled Mean Group (PMG) estimator, which involves both pooling and averaging (Pesaran et al., 1999). The MG approach consists of estimating separate regressions for each country and computing averages of the country-specific coefficients (Evans, 1997; Lee et al., 1997). This allows for heterogeneity of all the parameters. In contrast, the MG estimator allows the intercepts, short-run coefficients and error variances to differ freely across groups, but the longrun coefficients are constrained to be the same. The group-specific short-run coefficients and the common long-run coefficients are computed by the pooled maximum likelihood estimation. Both these estimators are appropriate for analyzing dynamic panels with large time and cross-section dimensions, and they have the advantage of accommodating both the long-run equilibrium and the possibly heterogeneous dynamic adjustment process.

We base our panel analysis on the unrestricted error correction $\operatorname{ARDL}(p, q)$ representation:

$$
\begin{aligned}
\Delta \ln y_{i t} & =\varphi_{i} y_{i t-1}+\beta_{i}^{\prime} x_{i t-1}+\sum_{j=1}^{p-1} \lambda_{i j} \Delta \ln y_{i t-j}+\sum_{q=1}^{q-1} \gamma^{\prime}{ }_{i j} \Delta \ln x_{i t-j}+\mu_{i}+\xi_{i t}, \\
i=1,2, \ldots, N ; t & =1,2, \ldots, T
\end{aligned}
$$

where $y_{i t}$ is a scalar dependent tax revenue variable, $x_{i t}$ is the $k \times 1$ vector of regressors for group $I$ (which includes GDP but also other potential controls), $\mu_{i}$ represents the fixed effects, $\varphi_{i}$ is a scalar coefficient on the lagged dependent variable. $\beta_{i}^{\prime}$ 's is the $k \times 1$ vector of coefficients on explanatory variables, $\lambda_{i j}$ 's are scalar coefficients on lagged first-differences of dependent variables, and $\gamma_{i j}$ 's are $k \times 1$ coefficient vectors on first-differences of explanatory variables and their lagged values. We assume that the disturbances $\xi_{i t}$ 's in the ARDL model are independently distributed across $i$ and $t$, with zero means and constant variances. Equation (6) means that developments in tax revenues can be explained by a distributed lag of order $p$ of the dependent 
variable, and a distributed lag of order $q$ of GDP. ${ }^{11}$ Assuming that $\varphi_{i}<0$ for all $i$, there exists a long-run relationship between $y_{i t}$ and $x_{i t}$ such as:

$$
\ln y_{i t}=\theta_{i}^{\prime} \ln x_{i t-1}+\eta_{i t}, i=1,2, \ldots, N ; t=1,2, \ldots, T
$$

where $\theta^{\prime}{ }_{i}=-\beta_{i}{ }^{\prime} / \varphi_{i}$ is the $k \times 1$ vector of the long-run coefficients, and $\eta_{i t}$ 's are stationary with possible non-zero means. Equation (6) can be rewritten as:

$$
\Delta \ln y_{i t}=\varphi_{i} \eta_{i t-1}+\sum_{j=1}^{p-1} \lambda_{i j} \Delta \ln y_{i t-j}+\sum_{q=1}^{q-1} \gamma^{\prime}{ }_{i j} \Delta \ln x_{i t-j}+\mu_{i}+\xi_{i t}, i=1,2, \ldots, N ; t=
$$

$1,2, \ldots, T$

where $\eta_{i t-1}$ is the error correction term given by (7), hence $\varphi_{i}$ is the error correction coefficient measuring the speed of adjustment towards the long-run equilibrium. ${ }^{12}$

\section{Data}

We use annual tax revenue data for an unbalanced panel of 30 Asian-Pacific countries between 1980 and $2017 .{ }^{13}$ In addition to aggregate tax revenue data (which we use excluding social security contributions), we focus on four specific tax categories that in the last year considered, 2017, account for more than 80 percent of tax revenues. We look specifically at: i) Personal Income Tax (PIT); ii) Corporate Income Tax (CIT); Taxes on Goods and Services (TGS); Trade Taxes (TT). ${ }^{14}$ These come from the World Bank's World Development Indicators. Data on GDP and inflation (CPI and deflator based) are retrieved from IMF's World Economic Outlook database. Summary statistics are displayed in Table A1 in the Appendix.

\footnotetext{
${ }^{11}$ The Bayesian Information Criteria was used to choose the optimal lag length and we found it to be equal to 1 for both $p, q$.

${ }^{12}$ Applied to a panel setting, this econometric approach borrows from the time series literature on vector error correction models (VECM). A VECM has the advantage of using both short run and long run information. The short run effect measures the immediate impact that a change in $\mathbf{X}_{\mathbf{t}}$ will have on change in $\mathbf{Y}_{\mathbf{t}}$. On the other hand $\varphi_{i}$ is the feedback effect or adjustment effect, and shows how much of the disequilibrium is being corrected i.e. the extent to which any disequilibrium in the previous period effects any adjustment.

${ }^{13}$ Complete list of countries is in the Appendix together with start and end date for tax revenues data.

${ }^{14}$ The number of observations per country and tax category varies based on data availability.
} 
In Figure 2, we plot the interquartile range for total tax revenue, PIT, CIT, TGS and TT for our entire sample of countries (all variables expressed in percent of GDP). ${ }^{15}$ We observe that while tax revenues increased from the early 2000s, there have taken a tow during the Global Financial Crisis and relatively flat since. Zooming in into the tax components, most of the growth in tax revenues over the last decades has been driven particularly by increases in CIT and TGS. PIT and TT, on the other hand, have remained generally flat. Yet again, it is interesting to note the drop in CIT around 2008-09 corresponding to the particularly negative impact of the Global Financial Crisis on the corporate sector. In contrast, no such fall is graphically visible in the case of TGS.

Figure 2. Inter-Quartile Range of Tax Revenues in Asia (percent GDP), 1980-2017

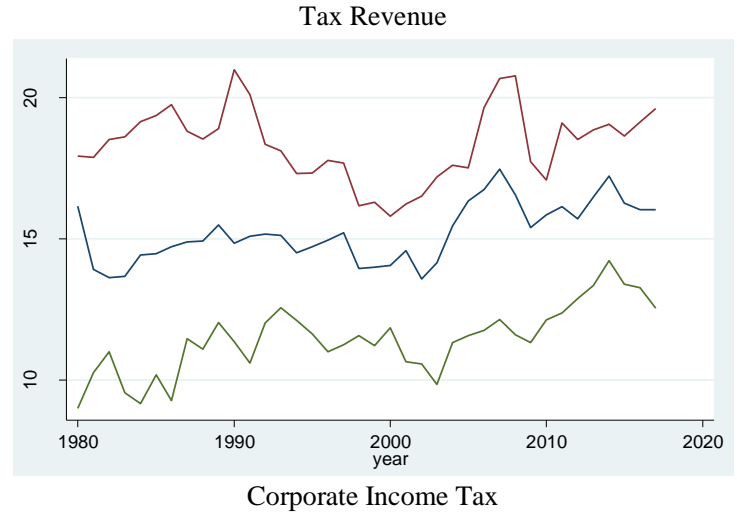

Personal Income Tax
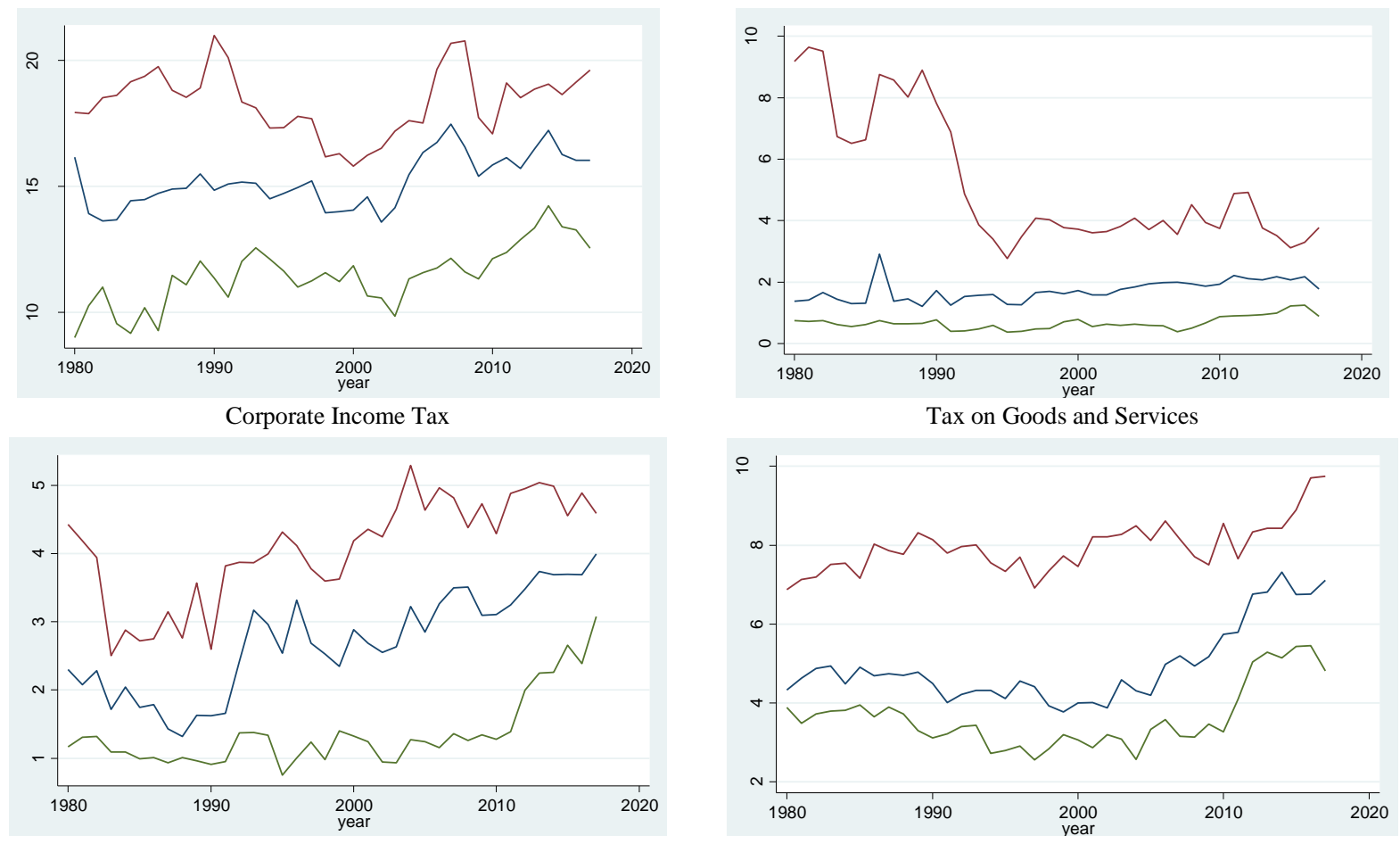

\footnotetext{
${ }^{15}$ Country specific individual charts for total tax revenue in percent of GDP are shown in Figure A1 in the Appendix. For an earlier discussion on the level and composition of tax revenues in several developing countries see Mahdavi (2008).
} 


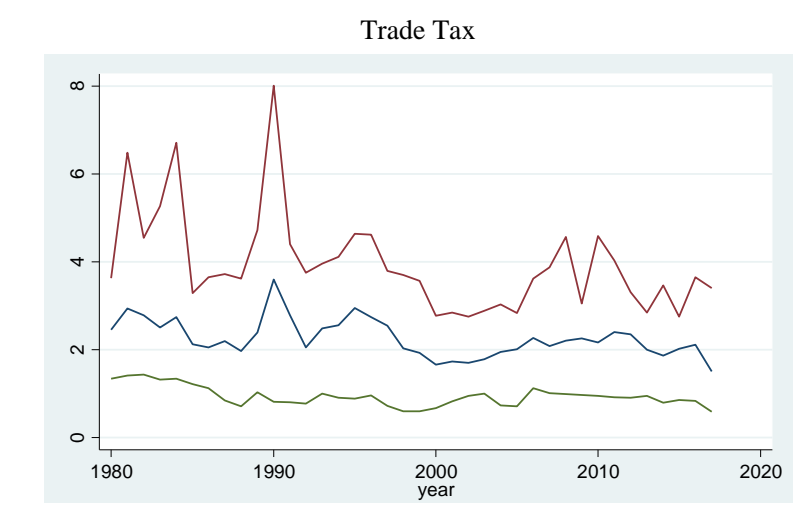

Note: Each panel plots the median (blue line) together with the $25^{\text {th }}$ and $75^{\text {th }}$ percentiles of the respective distributions (green and red lines respectively).

Source: author's calculations.

\section{Empirical Results}

\subsection{Baseline Estimates}

Equation (7) is first estimated by means of the mean group estimator for aggregate tax revenues. Details of the country specific estimates are presented in Table 1. The average long run buoyancy estimate is 1.19 while the corresponding short run buoyancy is 1.16 .

The standard deviation is slightly larger in the short-run buoyancy than in the short run one. Bangladesh, Bhutan, Brunei, Cambodia, Laos, Pakistan, Vietnam, Fiji, Papua New Guinea, Tonga and Micronesia, all display long-run buoyancies statistically significant higher than one. Higher than one buoyancies for Bangladesh was also found in the study by Ahmed and Mohamed (2010). For Pakistan, our results are in line with those Shaikh (2012) who, looking at the period 1974-2009, found the buoyancy of the Pakistanis tax system to be higher than unity. ${ }^{16}$ This means that for these countries growth has improved fiscal sustainability over time. For the remainder list of countries, almost all yielded a long run buoyancy statistically not different from unity. In Japan, Brunei, Singapore and Thailand, the tax system has acted as a good automatic stabilizer as evidenced by short-run buoyancies statistically larger than one. ${ }^{17}$ For the remainder of the countries, tax systems are mostly neither good nor bad automatic stabilizers. Our findings for India are broadly in line with Upender's (2008) that found a buoyancy coefficient not strictly larger than

\footnotetext{
${ }^{16}$ Shaikh (2012) attributed such result to diversification and deepening of the manufacturing sector and shrinking of the agricultural sector.

${ }^{17}$ As far as Thailand is concerned, Bartolich (2005) carefully examined the country's tax system and discussed the different set of tax reforms enacted since the 1997 Asian Crisis.
} 
unity in the 1992 post-tax reform period. The speed of adjustment coefficient is the lowest (largest) in the Philippines (Tuvalu) meaning that the adjustment towards its long-term value is slow (fast).

Table 1. Overall Tax Buoyancy in Asian-Pacific Countries, 1980-2017

\begin{tabular}{|c|c|c|c|}
\hline Country & Long run buoyancy & Short run buoyancy & Speed of Adjustment \\
\hline Japan & $1.085 * * *$ & $2.158 * * *$ & $-0.312 * * *$ \\
\hline Australia & $0.953 * * *$ & $0.942 * * *$ & -0.151 \\
\hline New Zealand & $0.974 * * *$ & $1.206 * * *$ & $-0.254 * *$ \\
\hline Bangladesh & $1.207 * * *$ & 0.396 & $-0.491 * * *$ \\
\hline Bhutan & $1.236^{* * * *}$ & 1.438 & $-0.439 * * *$ \\
\hline Brunei Darussalam & $1.565 * * *$ & $2.063 * * *$ & $-0.597 * * *$ \\
\hline Myanmar & $1.230 * * *$ & -0.767 & $-0.590 * * *$ \\
\hline Cambodia & $1.443 * * *$ & $1.418 * * *$ & $-0.481 * *$ \\
\hline Sri Lanka & $0.938 * * *$ & $1.021 * * *$ & $-0.358 * *$ \\
\hline India & $1.050 * * *$ & $1.224 * * *$ & -0.192 \\
\hline Indonesia & $0.935 * * *$ & $1.059 * * *$ & $-0.588 * * *$ \\
\hline Laos & $1.308 * * *$ & $1.153 * * *$ & $-0.536 * *$ \\
\hline Malaysia & $0.868 * * *$ & $0.713 * *$ & $-0.485 * * *$ \\
\hline Maldives & $0.994 * * *$ & $1.107 * * *$ & $-0.217 * * *$ \\
\hline Nepal & 2.779 & $1.125 * * *$ & -0.013 \\
\hline Pakistan & $1.511 * * *$ & $1.338 * * *$ & $-0.504 *$ \\
\hline Philippines & $1.059 * * *$ & $1.650 * * *$ & $-0.185^{*}$ \\
\hline Singapore & $1.045 * * *$ & $1.556 * * *$ & -0.134 \\
\hline Thailand & $1.099 * * *$ & $1.728 * * *$ & $-0.374 * * *$ \\
\hline Vietnam & $1.074 * * *$ & $0.797 * * *$ & $-0.327 * * *$ \\
\hline Solomon Islands & $1.074 * * *$ & $1.127 * * *$ & -0.124 \\
\hline Fiji & $1.111 * * *$ & $1.351 * * *$ & $-0.355 * *$ \\
\hline Kiribati & $1.203 * * *$ & 0.475 & $-0.231 *$ \\
\hline Vanuatu & $0.971 * * *$ & $1.214 * * *$ & $-0.334 * * *$ \\
\hline Papua New Guinea & $1.096^{* * * *}$ & $0.745 * * *$ & $-0.500 * * *$ \\
\hline Tonga & $1.178 * * *$ & $1.304 * * *$ & $-0.445^{* * *}$ \\
\hline Marshall Islands & $1.135 * * *$ & $0.911 * *$ & $-0.499 *$ \\
\hline Micronesia & $1.487 * * *$ & $1.489^{*}$ & $-0.996 * * *$ \\
\hline Tuvalu & $1.039 * * *$ & $1.981 * * *$ & $-1.291 * * *$ \\
\hline Mongolia & $0.992 * * *$ & $0.933 * * *$ & $-0.203^{*}$ \\
\hline
\end{tabular}

Note: Estimation of Equation (7) by MG estimator (see main text for details). Bold italic means statistically greater than one at 5 percent level. Standard errors in parenthesis. *,**,*** denote statistical significance at the 10,5 and 1 percent levels, respectively.

We repeat the same country-specific estimation of equation (7) now for the PIT, CIT, TGS and TT and summarize the country-specific information by constructing four histograms. Countryspecific results are displayed in the Appendix Tables A2-A5. We can observe that there are wide variations in the degree of buoyancy across the four tax categories. Figure 3 shows that the longrun buoyancy mode is between 0.8 and 1.4, while the short-run buoyancy mode is between 1 and 1.7. 
Figure 3. Histogram of Country Specific Buoyancy Estimates (relative frequency, in percent)

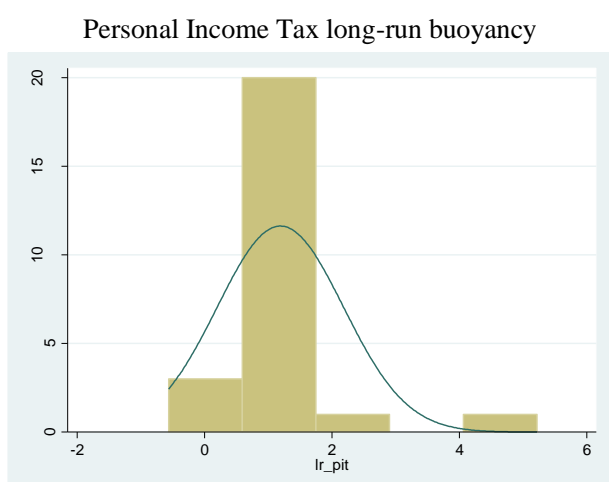

Corporate Income Tax long-run buoyancy

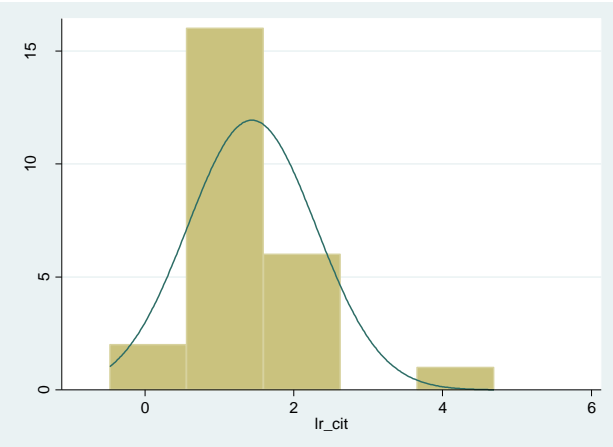

Tax on Goods and Services long-run buoyancy

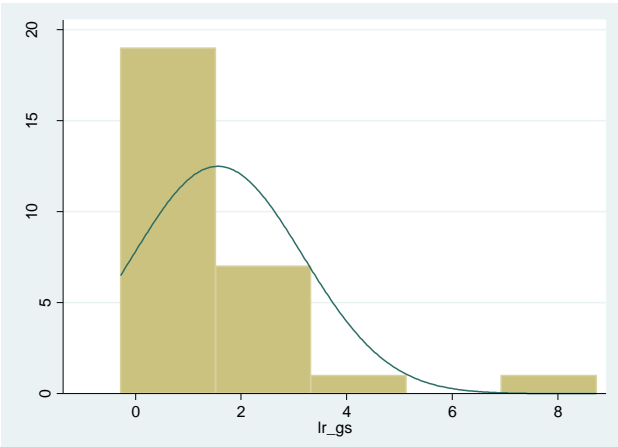

Trade Tax long-run buoyancy

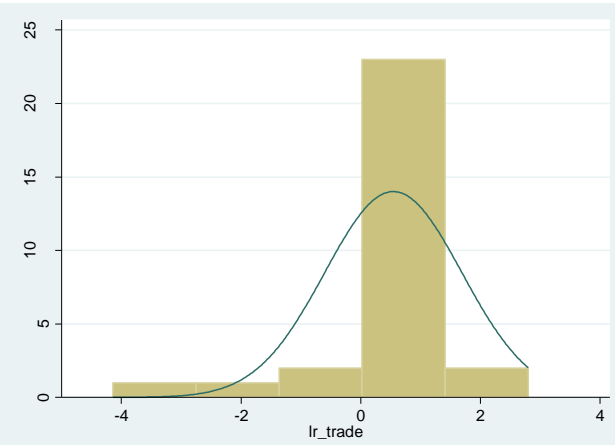

Personal Income Tax short-run buoyancy

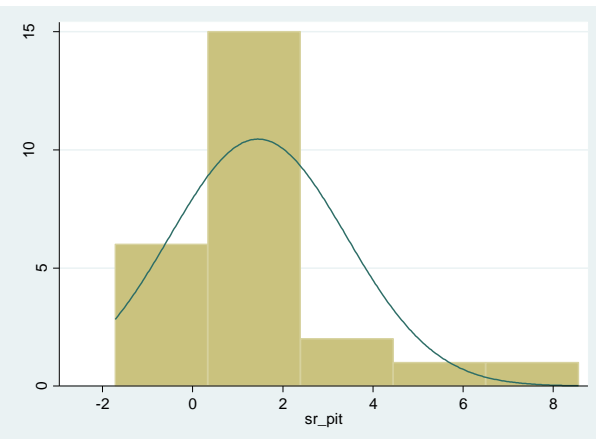

Corporate Income Tax short-run buoyancy

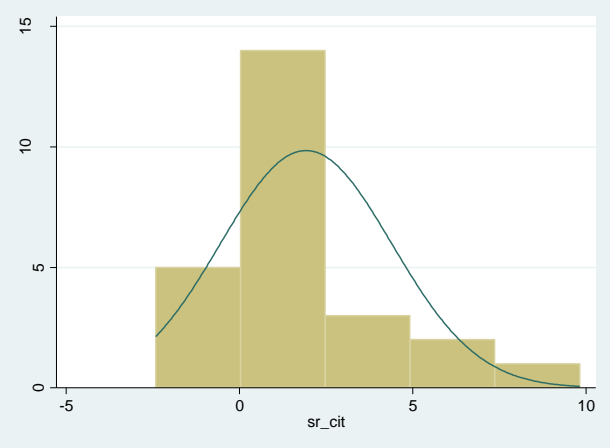

Tax on Goods and Services short-run buoyancy

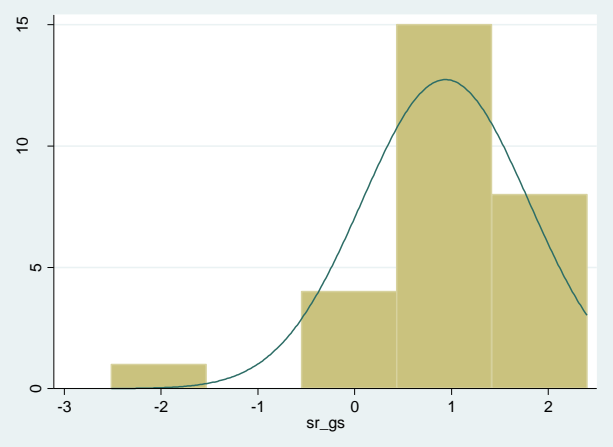

Trade Tax short-run buoyancy

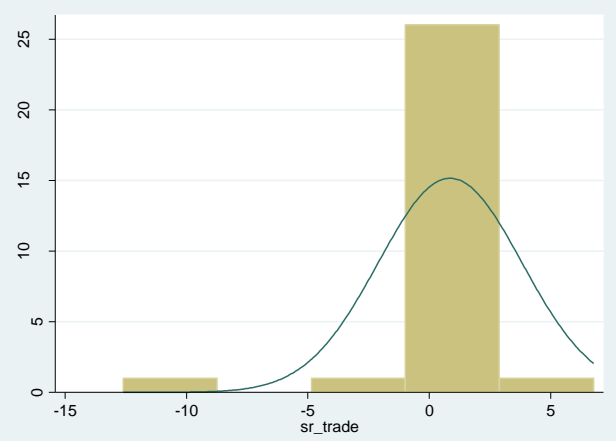

Note: LR and SR denote long-run and short-run buoyancy coefficients, respectively. Source: author's calculations. 
We continue, now with the entire panel and estimate equation (7) using data for total tax revenue and the four tax categories. We estimate coefficients for short-run, long-run and the speed of adjustment using either a MG estimator. Results shown in Table 2 suggest that, on average, long-run buoyancies for overall tax revenues and CIT are statistically larger than one. This means that CIT has contributed to improving fiscal sustainability over time. The remaining coefficients (including short-term buoyancies) are not statistically different from one, except in the case of trade taxes. Hence, between PIT, CIT or TGS there is no single best source of automatic stabilizers in these group of countries taken together. The speed of adjustment is the lowest (largest) in TT (CIT) meaning that the adjustment towards its long-term value is slow (fast).

Table 2. Tax Buoyancy, Mean Group Estimator

\begin{tabular}{r|ccccc}
\hline \multicolumn{1}{c}{ Tax revenues } & PIT & CIT & $T G S$ & $T T$ \\
\hline Long run buoyancy & $\mathbf{1 . 1 5 9 * * *}$ & $\mathbf{1 . 1 9 1 * * *}$ & $\mathbf{1 . 4 3 5 * * *}$ & $\mathbf{1 . 5 6 0}^{* * *}$ & $0.546^{* *}$ \\
& $(0.068)$ & $(0.198)$ & $(0.173)$ & $(0.304)$ & $(0.213)$ \\
Short run buoyancy & $\mathbf{1 . 2 1 6 * * *}$ & $\mathbf{1 . 4 5 2 * * *}$ & $\mathbf{1 . 9 2 3}^{* * *}$ & $\mathbf{0 . 9 3 9 * * *}$ & 0.858 \\
& $(0.112)$ & $(0.392)$ & $(0.496)$ & $(0.163)$ & $(0.549)$ \\
Speed of adjustment & -0.145 & $-0.554 * * *$ & $-0.560 * * *$ & $-0.413 * * *$ & $-0.385 * * *$ \\
& $(0.266)$ & $(0.105)$ & $(0.096)$ & $(0.049)$ & $(0.070)$ \\
& & & & & \\
Observations & 911 & 548 & 575 & 691 & 704 \\
\hline
\end{tabular}

Note: Estimation of Equation (7) by the MG estimator (see main text for details). Bold italic means statistically greater than one at 5 percent level; bold means statistically not different from one at 5 percent level. Standard errors in parenthesis. *, **, *** denote statistical significance at the 10,5 and 1 percent levels, respectively.

\subsection{Sensitivity and Robustness}

In this sub-section we subject our baseline estimations to several sensitivity and robustness checks.

\subsubsection{Sensitivity to alternative specifications, samples and estimators}

We start with the use of the PMG estimator as an alternative. Redoing Table 2 with this estimator gets us the results displayed in Table 3. The differences are that now we get a short-run buoyancy for CIT statistically larger than one. Moreover, now both short and long-run buoyancy coefficients for TT are not statistically different from one. But overall, the tax revenue result we found before is kept. 
Table 3. Tax Buoyancy, Pooled Mean Group Estimator

\begin{tabular}{r|ccccc}
\hline & Tax revenues & $P I T$ & $C I T$ & $T G S$ & $T T$ \\
\hline Long run buoyancy & $\mathbf{1 . 0 8 2} * * *$ & $\mathbf{1 . 2 5 8} * * *$ & $\mathbf{1 . 4 9 0} * * *$ & $\mathbf{1 . 0 1 6}^{* * * *}$ & $\mathbf{1 . 0 0 7 * * *}$ \\
& $(0.013)$ & $(0.019)$ & $(0.039)$ & $(0.014)$ & $(0.020)$ \\
Short run buoyancy & $\mathbf{1 . 0 7 6} * * *$ & $\mathbf{0 . 9 8 7 * * *}$ & $\mathbf{2 . 1 0 7 * * *}$ & $\mathbf{0 . 7 9 2} * * *$ & $\mathbf{1 . 0 4 3} * * *$ \\
& $(0.143)$ & $(0.241)$ & $(0.442)$ & $(0.244)$ & $(0.337)$ \\
Speed of adjustment & $-0.263 * * *$ & $-0.326 * * *$ & $-0.329 * * *$ & $-0.213 * * *$ & $-0.244 * * *$ \\
& $(0.048)$ & $(0.063)$ & $(0.062)$ & $(0.041)$ & $(0.040)$ \\
& & & & & \\
Observations & 911 & 548 & 575 & 691 & 704 \\
\hline
\end{tabular}

Note: Estimation of Equation (7) by the PMG estimator (see main text for details). Bold italic means statistically greater than one at 5 percent level; bold means statistically not different from one at 5 percent level. Standard errors in parenthesis. *, **, *** denote statistical significance at the 10,5 and 1 percent levels, respectively.

A second sensitivity exercise concerns the fact that when estimating Equation (7), in which we use nominal changes in tax revenues and nominal GDP, we include both a price component and a real component. Adding inflation - based on the GDP deflator - as an additional control variable is important to assess whether tax buoyancy is independent or not from price developments. ${ }^{18}$ If the latter, the same relationship would be obtained if real variables were used instead. Results in Table 4 for TGS show that inflation enters with a significant positive coefficient, particularly in the long-run. Moreover, the coefficients for buoyancy are now smaller (in magnitude) than before. Hence, tax buoyancy does not appear neutral with respect to inflation, meaning that tax buoyancy in real terms is smaller than in nominal.

${ }^{18}$ Using CPI-based inflation instead does not qualitatively change our results. 


\section{Table 4. Tax Buoyancy, Mean Group Estimator, controlling for inflation}

\begin{tabular}{r|ccccc}
\hline & Tax revenues & $P I T$ & CIT & TGS & TT \\
\hline Long run buoyancy & $\mathbf{1 . 0 0 2 * * *}$ & $\mathbf{0 . 9 7 7 * * *}$ & $\mathbf{1 . 5 5 6}^{* * *}$ & $0.895^{* *}$ & $\mathbf{0 . 9 3 2 * * *}$ \\
& $(0.123)$ & $(0.100)$ & $(0.171)$ & $(0.454)$ & $(0.242)$ \\
Short run buoyancy & $\mathbf{1 . 0 1 6}^{* * *}$ & 2.723 & $\mathbf{2 . 3 7 0 * * *}$ & -2.713 & -5.576 \\
& $(0.171)$ & $(2.222)$ & $(0.669)$ & $(3.778)$ & $(5.965)$ \\
Speed of adjustment & $-0.292^{* * *}$ & $-0.574^{* * *}$ & $-0.403 * * *$ & $-0.410^{* * *}$ & $-0.366^{* * *}$ \\
& $(0.080)$ & $(0.186)$ & $(0.098)$ & $(0.064)$ & $(0.075)$ \\
Long run price effect & 0.810 & -0.015 & -0.000 & $0.196^{*}$ & -0.076 \\
& $(1.217)$ & $(0.029)$ & $(0.020)$ & $(0.116)$ & $(0.071)$ \\
Short run price effect & 0.024 & -0.010 & -0.013 & 0.020 & 0.050 \\
& $(0.287)$ & $(0.017)$ & $(0.015)$ & $(0.029)$ & $(0.042)$ \\
& 908 & 544 & 573 & 690 & 702 \\
\hline
\end{tabular}

Note: Estimation of Equation (7) by the MG estimator (see main text for details). Bold italic means statistically greater than one at 5 percent level; bold means statistically not different from one at 5 percent level. Standard errors in parenthesis. *, **, *** denote statistical significance at the 10,5 and 1 percent levels, respectively.

Buoyancy of the tax system could be biased if changes in tax revenues and GDP are correlated with changes in tax policy parameters, such as tax rates or exemptions. To account for this possibility, we add to our equation (7) developments in tax rates as a control variable. ${ }^{19}$ This is important in light of several tax reforms enacted since the 1990s in several countries. ${ }^{20}$ Results including tax rates as a control are displayed in Table 5. Controlling for the top PIT rate does not significantly change long-run tax buoyancy estimates. For the CIT, controlling for corresponding tax rates, significantly increases the point estimate in the long-run (it becomes statistically larger than one). No major changes take place regarding short-run buoyancies. ${ }^{21}$

\footnotetext{
${ }^{19}$ Note, however that the country and time coverage of tax rates is smaller than that of general tax revenue data, so when used in regression analysis, this reduces the total number of observations. Tax rates are retrieved from the IMF's Tax Policy Division database.

${ }^{20}$ See Ahmad and Stern for a discussion of theory and practice of tax reforms in developing countries.

${ }^{21}$ Note that in addition to adding inflation and tax rates as potentially important regressors to our main specification, other factors (e.g. capacity of tax administration, institutional quality, etc.) could also be considered. However, we do not believe that the omitted variable bias is that large as evidenced by the robustness exercises conducted.
} 
Table 5. Tax Buoyancy of Revenue Components, controlling for tax rates

\begin{tabular}{r|cc|cc|cc}
\hline \multicolumn{3}{|c|}{ Personal Income Tax } & \multicolumn{2}{c|}{ Corporate Income Tax } & \multicolumn{2}{c}{ Taxes on Goods and Services } \\
\hline & No tax rate & tax rate & No tax rate & tax rate & No tax rate & tax rate \\
\hline Long run buoyancy & $\mathbf{1 . 1 9 1} * * *$ & $\mathbf{0 . 9 3 5 * * *}$ & $\mathbf{1 . 4 3 5} * * *$ & $\mathbf{1 . 7 5 4} * * *$ & $\mathbf{1 . 5 6 0} * * *$ & -1.266 \\
& $(0.198)$ & $(0.151)$ & $(0.173)$ & $(0.346)$ & $(0.304)$ & $(2.509)$ \\
Short run buoyancy & $\mathbf{1 . 4 5 2} * * *$ & $\mathbf{1 . 3 4 2} * * *$ & $\mathbf{1 . 9 2 3} * * *$ & $\mathbf{1 . 7 3 1 * *}$ & $\mathbf{0 . 9 3 9 * * *}$ & $\mathbf{0 . 8 0 7 * * *}$ \\
& $(0.392)$ & $(0.395)$ & $(0.496)$ & $(0.544)$ & $(0.163)$ & $(0.214)$ \\
Speed of adjustment & $-0.554 * * *$ & $-0.779 * * *$ & $-0.560 * * *$ & $-0.585^{* * *}$ & $-0.413 * * *$ & $-0.691 * * *$ \\
& $(0.105)$ & $(0.297)$ & $(0.096)$ & $(0.060)$ & $(0.049)$ & $(0.132)$ \\
Observations & & & & & & 464 \\
\hline
\end{tabular}

Note: Estimation of Equation (7) by PMG estimator (see main text for details). Bold italic means statistically greater than one at 5 percent level; bold means statistically not different from one at 5 percent level. Standard errors in parenthesis. *, **, *** denote statistical significance at the 10,5 and 1 percent levels, respectively.

Given the long time-span covered, has the buoyancy of different taxes changed over time? We answer this question by splitting the time-span halfway, before and after 1999. During the 1980s and 1990s there was little short-run action as far as tax buoyancy is concerned. For PIT, CIT and TT short-run buoyancy was not statistically different from zero. This changed in the most recent couple of decades with them becoming larger in magnitude and statistically not different from one. This suggested that the tax system has made progress over time. Also, in the more recent period long-run buoyancy for TGS is statistically larger than one, signaling that this tax component started contributing more towards fiscal sustainability as time went by. Little differences can be seen between the two periods as far as TT are concerned. 
Table 6. Tax Buoyancy, Mean Group Estimator

\begin{tabular}{|c|c|c|c|c|c|}
\hline & Tax revenues & $P I T$ & CIT & $T G S$ & $T T$ \\
\hline Time period & & & 1980-1998 & & \\
\hline Long run buoyancy & $\begin{array}{c}1.000 * * * \\
(0.066)\end{array}$ & $\begin{array}{c}\mathbf{1 . 0 0 6}^{* * * *} \\
(0.176)\end{array}$ & $\begin{array}{c}\mathbf{0 . 9 8 5} * * * \\
(0.367)\end{array}$ & $\begin{array}{c}\mathbf{0 . 9 8 6}^{* *} \\
(0.387)\end{array}$ & $\begin{array}{l}3.058 \\
(2.504)\end{array}$ \\
\hline Short run buoyancy & $\begin{array}{c}\text { 1.047*** } \\
(0.153)\end{array}$ & $\begin{array}{c}0.745 \\
(0.642)\end{array}$ & $\begin{array}{c}0.678 \\
(0.456)\end{array}$ & $\begin{array}{l}0.891 * \\
(0.517)\end{array}$ & $\begin{array}{l}-0.011 \\
(0.948)\end{array}$ \\
\hline Speed of adjustment & $\begin{array}{c}-0.257 \\
(0.355)\end{array}$ & $\begin{array}{c}-0.673 * * * \\
(0.167)\end{array}$ & $\begin{array}{c}-0.843 * * * \\
(0.237)\end{array}$ & $\begin{array}{c}-0.726 * * * \\
(0.118)\end{array}$ & $\begin{array}{c}-0.705 * * * \\
(0.204)\end{array}$ \\
\hline Observations & 357 & 176 & 194 & 248 & 266 \\
\hline Time period & & & 1999-2017 & & \\
\hline Long run buoyancy & $\begin{array}{c}1.108 * * * \\
(0.062)\end{array}$ & $\begin{array}{c}\mathbf{1 . 2 3 8} * * * \\
(0.254)\end{array}$ & $\begin{array}{c}\mathbf{0 . 9 2 7} * * \\
(0.421)\end{array}$ & $\begin{array}{c}.249 * * * * \\
(0.125)\end{array}$ & $\begin{array}{c}0.469 \\
(0.333)\end{array}$ \\
\hline Short run buoyancy & $\begin{array}{c}1.384 * * * \\
(0.143)\end{array}$ & $\begin{array}{c}1.714 * * * \\
(0.500)\end{array}$ & $\begin{array}{c}\mathbf{1 . 4 8 3} * * * \\
(0.413)\end{array}$ & $\begin{array}{c}\mathbf{1 . 0 3 5}^{* * * *} \\
(0.207)\end{array}$ & $\begin{array}{c}0.668 \\
(0.680)\end{array}$ \\
\hline Speed of adjustment & $\begin{array}{c}-0.456 * * * \\
(0.043)\end{array}$ & $\begin{array}{c}-0.525^{* * *} \\
(0.119)\end{array}$ & $\begin{array}{c}-0.520 * * * \\
(0.067)\end{array}$ & $\begin{array}{c}-0.634 * * * \\
(0.087)\end{array}$ & $\begin{array}{c}-0.639 * * * \\
(0.086)\end{array}$ \\
\hline Observations & 425 & 264 & 290 & 341 & 343 \\
\hline
\end{tabular}

Note: Estimation of Equation (7) by the MG estimator (see main text for details). Bold italic means statistically greater than one at 5 percent level; bold means statistically not different from one at 5 percent level. Standard errors in parenthesis. *, **, *** denote statistical significance at the 10, 5 and 1 percent levels, respectively.

\subsubsection{Tax Buoyancy in Good and Bad Times}

Now we try to understand variations in the stabilization role of taxation during periods of economic expansion and economic contraction. We begin with an event-study type exercise, by plotting the total tax revenue-to-GDP ratios (and the four tax categories considered in this paper) around recessions (identified as years of negative GDP growth), as well as one and two years before/after the episode. Looking at Figure 4, the first observation is that overall tax revenues decreased immediately once the recession takes place and it takes about two years to start recovering a bit again. Looking at the four different tax categories, PIT and TGS fall contemporaneously at time $t$ while CIT falls with a lag of one period following a recession (we only observe a fall from $t$ to $t+1$ ) but it recovers in $t+2$. Trade taxes seem generally unaffected by domestic recessions. 
Figure 4. Tax Revenue and categories (percent of GDP) around Recessions

Total Tax Revenues

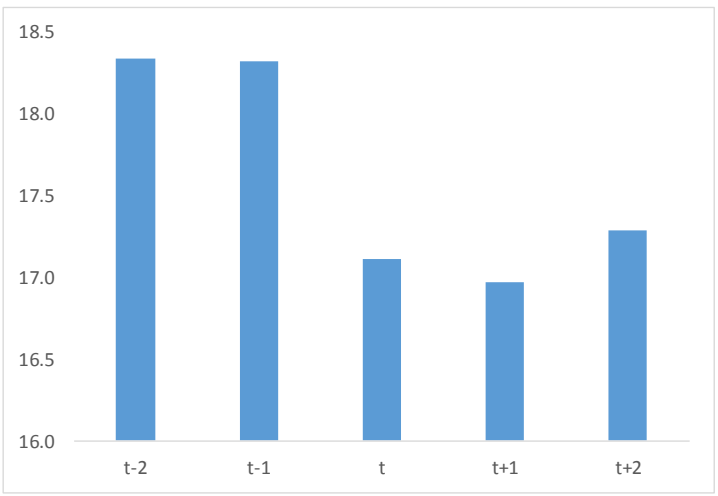

Corporate Income Tax
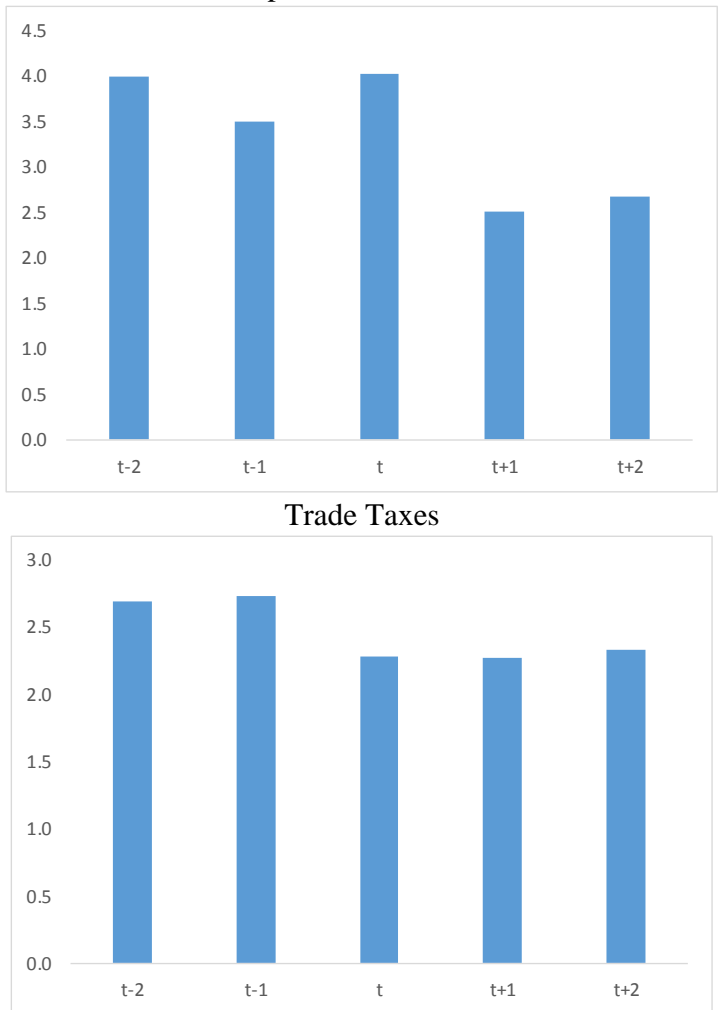

Personal Income Tax

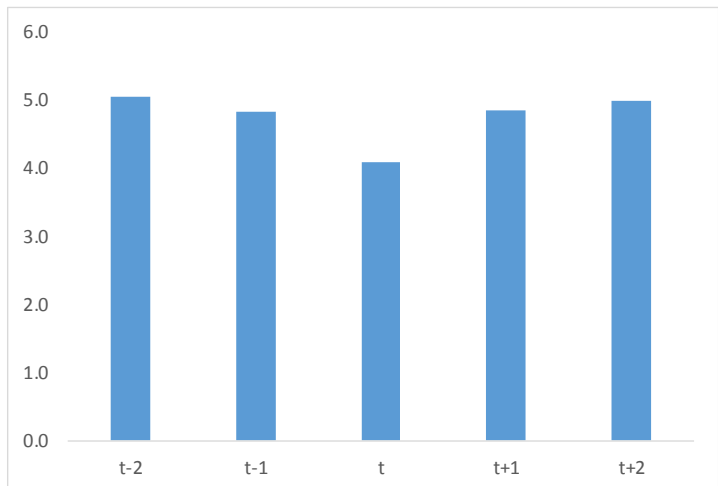

Tax on Goods and Services

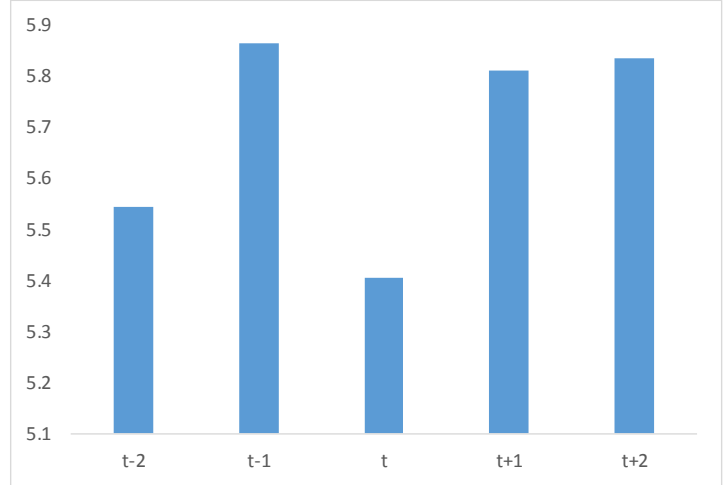

Note: " $\mathrm{t}$ " is in years and it corresponds to the average of the relevant tax revenue in the first recession year. " $\mathrm{t}+1$ " (" $\mathrm{t}+2$ ") correspond to the value of the ratio of the relevant tax revenue to GDP one (two) year after the beginning of the recession. Mutatis mutandis for "t-1" ("t-2").

Source: author's calculations.

To empirically explore whether tax buoyancy varies depending on the phase of the business cycle, the following alternative short-run non-linear regression is estimated:

$\Delta \ln y_{i t}=\alpha_{i}^{k}+\beta_{k}^{\text {recession }} \cdot Y(z) \cdot \Delta \ln x_{i t}+\beta_{k}^{\text {expansion }} \cdot(1-Y(z)) \cdot \Delta \ln x_{i t}+\mu_{i}+\eta_{t}+\varepsilon_{i, t}^{k}$ 
with $Y\left(z_{i t}\right)=\frac{\exp \left(-\gamma z_{i t}\right)}{1+\exp \left(-\gamma z_{i t}\right)}, \quad \gamma>0$

in which $z_{i t}$ is an indicator of the state of the economy normalized to have zero mean and unit variance. The weights assigned to each regime vary between 0 and 1 according to the weighting function $F($.$) , so that F\left(z_{i t}\right)$ can be interpreted as the probability of being in a given state of the economy. The coefficients $\beta_{k}^{\text {recession }}$ and $\beta_{k}^{\text {expansion }}$ capture the buoyancy impact at each horizon $k$ in cases of extreme recessions $\left(F\left(z_{i t}\right) \approx 1\right.$ when $z$ goes to minus infinity) and booms ( $1-$ $F\left(z_{i t}\right) \approx 1$ when $\mathrm{z}$ goes to plus infinity), respectively. ${ }^{22}$ We choose $\gamma=1.5$, following Auerbach and Gorodnichenko (2012), so that the economy spends about 20 percent of the time in a recessionary regime-defined as $F\left(z_{i t}\right)>0.8 .{ }^{23}$ This is equivalent to the smooth transition autoregressive (STAR) model developed by Granger and Teräsvirta (1993) to inspect nonlinearities. ${ }^{24}$ Compared with a model in which each dependent variable would be interacted with a measure of the business cycle position, an advantage of this approach is the fact that it permits a direct test of whether the tax buoyancy varies in recessions and expansions. By having the $F($.$) varying across a continuum of states this makes the state-contingent buoyancy to change$ smoothly making the estimations in each state more stable and precise.

The question now is what to use as an indicator for the variable $z_{i t}$ ? Commonly, real GDP growth is used as a proxy for the state of the economy. We use this as a baseline option. Then introduce a further innovation which is to obtain a new measure of the output gap for each country based on the new filtering technique suggested by Hamilton (2018). Mindful of the criticisms surrounding the popular use of the Hodrick-Prescott (HP) filter (such as the identification of spurious cycles) (Harvey and Jaeger, 1993; Cogley and Nason, 1995), Hamilton's (2018) method to extract the cyclical and trend component of a generic variable $x_{t}$ (denoted $x^{c}{ }_{t}$ and $x^{\tau}{ }_{t}$, respectively), consists of estimating the following:

$$
x_{t+h}=\gamma_{0}+\sum_{j=0}^{k} \gamma_{j}+x_{t-j}+u_{t+h}
$$

where $x_{t}=x^{\tau}{ }_{t}+x^{c}{ }_{t}$.

\footnotetext{
${ }^{22} F\left(z_{i t}\right)=0.5$ is the cutoff between weak and strong economic activity.

${ }^{23}$ Our results hardly change when using alternative values of the parameter $\gamma$, between 1 and 6 .

${ }^{24}$ See Singh $(2012,2014)$ and Lopes and Zsurkis (2019) for a review and discussion of nonlinear models.
} 
The non-stationary part of the regression provides the cyclical component:

$$
x_{t}^{c}=\widehat{u_{t}}
$$

while the trend is given by

$$
x_{t}^{\tau}=\widehat{\gamma_{0}}+\sum_{j=0}^{k} \widehat{\gamma_{j}}+x_{t-h-j}
$$

Hamilton (2018) suggests that $h$ and $k$ should be chosen such that the residuals from equation (8) are stationary and points out that, for a broad array of processes, the fourth differences of a series are indeed stationary. We choose $h=2$ and $k=3$, which is line with the dynamics seen in real GDP. ${ }^{25}$

Table 7. Asymmetric Short-term Buoyancy over the Business Cycle

\begin{tabular}{r|cc|cc}
\hline Type of revenue & Economic Expansion & Economic Recession & Economic Expansion & Economic Recession \\
\hline Approach & \multicolumn{2}{|c|}{ STAR based on Real GDP growth } & \multicolumn{2}{c}{ STAR based on Hamilton OG } \\
\hline Tax Revenues & $0.912^{* * *}$ & $1.337^{* * *}$ & $1.101^{* * *}$ & $1.230^{* * *}$ \\
& $(0.057)$ & $(0.064)$ & $(0.088)$ & $(0.051)$ \\
PIT & $1.065^{* * *}$ & $1.336^{* * *}$ & $1.050^{* * *}$ & $1.463^{* * * *}$ \\
& $(0.307)$ & $(0.215)$ & $(0.238)$ & $(0.200)$ \\
CIT & $1.337^{* * *}$ & $1.334^{* * *}$ & $1.316^{* * *}$ & $1.353^{* * * *}$ \\
& $(0.214)$ & $(0.285)$ & $(0.239)$ & $(0.213)$ \\
TGS & $0.958^{* * *}$ & $1.081^{* * *}$ & $1.091^{* * *}$ & $1.111^{* * *}$ \\
& $(0.242)$ & $(0.181)$ & $(0.205)$ & $(0.195)$ \\
Trade & $0.727^{* * *}$ & $1.336^{* * *}$ & $0.642^{* * *}$ & $1.125^{* * *}$ \\
& $(0.156)$ & $(0.202)$ & $(0.247)$ & $(0.153)$ \\
\hline
\end{tabular}

Note: Estimation of Equation (8). Standard errors in parenthesis. *,**,*** denote statistical significance at the 10,5 and 1 percent levels, respectively.

Results are shown in Table 7. Buoyancy is generally larger during recessions than during times of economic expansions. This is particularly true in the cases of PIT and TT: this tax category on average seems to work better as automatic stabilizer in bad times compared to good times. This result is more broadly confirmed by Furceri and Jalles (2018) who found that the overall impact of fiscal stabilization (measured with a proxy of the degree of fiscal counter-cyclicality) was larger

${ }^{25}$ Summary statistics of the Hamilton-based output gap is shown in Table A1 in the Appendix. 
during recessionary periods. Results are qualitatively similar between the two ways to choose for an indicator of economic activity (either real GDP growth or the Hamilton-based output gap).

\section{Conclusion and Policy Implications}

Over the last few decades, the different Asian tax systems experienced various changes of individual taxes and major reforms thought to improve overall revenue collection, improve equity and fairness, and stabilize the economy. However, these efforts have had differentiated impacts across the region. In this paper, we empirically examined the short and long run tax buoyancies of 30 Asian-Pacific countries between 1980 and 2017 using recent panel data techniques.

On average, in this group of countries tax revenues have been increasing over the last decades particularly driven by CIT and TGS, despite the negative toll following the Global Financial Crisis. Using Mean Group estimators, we then found that the short-run buoyancy is 1.22 and statistically not different from one, while the long-run buoyancy is 1.16 and statistically larger than one (driven by a high CIT buoyancy). In 11 out of 30 countries long run tax buoyancies are statistically significant higher than one. This means that for these countries, growth has improved fiscal sustainability over time. For the remainder set of countries, almost all yielded a long run buoyancy statistically not different from unity. Because over the long run revenue tend to remain constant, as a share of GDP, an implication of our findings is that permanent increases in the ratio of spending-to-GDP (that do not improve structural conditions or human capital) should be accompanied by reforms aimed at mobilizing revenues, in order to avoid a permanent deterioration in the fiscal balance. In addition, in only 4 out of 30 countries the tax system has acted as a good automatic stabilizer as evidenced by short-run buoyancies statistically larger than one. The use of cyclically adjusted fiscal indicators could improve the efficiency of tax decision-making in these countries. Disaggregating tax revenues, between PIT, CIT or TGS there is no single best source of automatic stabilizers in these group of countries taken together. Results are robust to the estimation with alternative estimators, the inclusion of inflation and tax rates. We also uncovered that buoyancies increased in magnitude and significance over time suggesting progress in these countries' tax systems. Finally, resorting to nonlinear estimations of short-run buoyancies contingent on the phase of the business cycle, we find that buoyancy is generally larger during 
recessions than during times of economic expansions (this is particularly true in the cases of PIT and TT).

A highly buoyant tax structure is important for any Asian country since it implies that tax revenue could increase without tampering with the tax rates and, hence, avoid tax evasion and undesired political consequences. It is essential for policy-makers to know which tax handle is more buoyant since heavier reliance on such taxes enhances the overall buoyancy of the system. A tax buoyancy coefficient lower than one may point towards problems related to the tax structure, administration or compliance. In countries characterized by low buoyancies, tax authorities should improve tax information systems to prevent tax evasion, enhance the evaluation of its performance and facilitate adequate macroeconomic planning and implementation. Moreover, measures need to be put in place to ensure a broader tax base. Such measures may include creating an enabling business environment for companies to flourish, making effort at improving productivity and wages, reducing personal income allowances and fringe benefits, rationalizing tax exemptions and identifying new items to bring into the tax net.

Future work could consider estimating time-varying buoyancies to better inspect the time dynamics and also provide country-year estimates that could be used in a fully-fledged panel to study their structural determinants. 


\section{References}

1. Ahmad, E., Stern, N. (1991), "The theory and practice of tax reforms in developing countries", Cambridge University Press.

2. Ahmed, Q., Mohammed, S. (2010), "Determinant of tax buoyancy: empirical evidence from developing countries", European Journal of Social Sciences, 13 (3)

3. Auerbach, A., Gorodnichenko, Y. (2012), "Fiscal multipliers in recession and expansion. In: Alesina, A., Giavazzi, F. (eds.) Fiscal Policy After the Financial Crisis. NBER Books, National Bureau of Economic Research Inc., Cambridge

4. Ayoki, M., M. Obwona, Ogwapur, M. (2005), "Tax reform and domestic revenue mobilization in Uganda", second draft. Washington D.C: Global Development Network.

5. Banerjee, A. (1999), "Panel Data Unit Roots and Cointegration: An Overview", Oxford Bulletin of Economics and Statistics, 61, 607-629.

6. Bartolich, M. (2005), "Tax systems and tax reforms in South and East Asia: Thailand", Department of Public and Environmental Economics, University of Pavia, Working Paper 399.

7. Bekoe, W., Danquah, M., Senahey, S. (2016), "Tax reforms and revenue mobilization in Ghana", Journal of Economic Studies, 43(4), 522-534.

8. Belinga V., Benedek, D. de Mooij, R., Norregaard, J. (2014), "Tax Buoyancy in OECD Countries, IMF Working Paper Series No. 110, Washington, D.C.

9. Bilqueees, F. (2004), "Elasticity and buoyancy of the tax system in Pakistan", Pakistan Development Review, 43(1), 73-93

10. Blanchard, O., Dell'Aricia, G., Mauro P. (2010), "Rethinking macroeconomic policy", IMF Staff Position Note 10/03, Washington, D.C.

11. Bouthevillan, C., P. Cour-Thimann, G., Van den Dool, P., Hernandez de Cos, Langenus, G., Mohr, M., Momigliano, S., Tujula, M. (2001), "Cyclically adjusted budget balances: an alternative approach", ECB Working Paper Series No. 77.

12. Bruckner, M. (2012), "An instrumental variables approach to estimating tax revenue elasticities: evidence from sub-Saharan Africa", Journal of Development Economics, 98(2), 220-227.

13. Chelliah, R., Baas, H., Kelly, M. (1975), "Tax Ratios and Tax Effort in Developing Countries, 196971", IMF Staff Papers, 22(1), 187-205

14. Chipeta, C. (1998), "The second economy and tax yields in Malawi”. AERC Research Paper No. 81.

15. Choudhry, N. (1979), "Measuring the Elasticity of Tax Revenue: A Divisia Index Approach", IMF Staff Papers, 26(1), 87-122.

16. Cogley, T., Nason, J. (1995), "Effects of the Hodrick-Prescott filter on trend and difference stationary time series Implications for business cycle research", Journal of Economic Dynamics and Control, 19(1-2), 253-278

17. Deli, Y., Rodriguez, A., Kostarakos, I., Varthalities, P. (2018), "Dynamic Tax revenue buoyancy estimates for a panel of OECD countries", ESRI Working Paper No. 592.

18. Evans, P. (1997), "How fast do economies converge", Review of Economics and Statistics, 46, 12511271.

19. Furceri, D., Jalles, J. T. (2018), "Fiscal Stabilization: Determinants and Effects", Ensayos sobre Politica Economica, 36(85), 137-151.

20. Giorno, C., Richardson, P., Van den Noord, P. (1995), "Estimating Potential Output, Output Gaps and Structural Budget Balances", OECD Working Paper 24

21. Girouard, N., Andre, C. (2005), "Measuring Cyclically-Adjusted Budget Balances for the OECD Countries", OECD Working Paper 434.

22. Granger, C., Terasvirta, T. (1993), "Modelling Nonlinear Economic Relationships", Oxford University Press.

23. Hamilton, J. (2018), Why you should never use the Hodrick-Prescott filter", Review of Economics and Statistics, 100(5), 831-843 
24. Harvey, A., Jaeger, A. (1993), "Detrending, stylized facts and the business cycle", Journal of Applied Econometrics, 8(3), 231-247

25. Im, K. S., Pesaran, M. H., Shin, Y. (2003), “Testing for unit roots in heterogeneous panels”, Journal of Econometrics, 115, 53- 74.

26. Jayawickrama, A. (2008), “An examination of the resiliency of Sri Lanka's tax system”, South Asia Economic Journal, 9.

27. Jha, S., Mallick, S., Park, D., Quising, P. (2014), "Effectiveness of countercyclical fiscal policy: evidence from developing Asia", Journal of Macroeconomics, 40, 82-98.

28. Lagravinese, R., Liberati, P., Sacchi, A. (2020), "Tax buoyancy in OECD countries: new empirical evidence", Journal of Macroeconomics, 103-189.

29. Lee, K., Pesaran, M. H., Smith, R. P. (1997), "Growth and convergence in a multi-country empirical stochastic Solow model", Journal of Applied Econometrics, 12, 357-392.

30. Lopes, A.S. and G.F. Zsurkis (2019), "Are Linear Models Really Un-useful to Describe Business Cycle Data?”, Applied Economics, 51(22), 2355-2376.

31. Lotz, J. R., Morss, E. R. (1967), "Measuring 'Tax Effort' in Developing Countries", IMF Staff Papers, $14,479-497$

32. Mahdavi, S. (2008), "The Level and Composition of Tax Revenue in Developing Countries: Evidence from unbalanced panel data", International Review of Economics and Finance, 17, 607-617.

33. Mourre, G., Princen, S. (2015), "Tax revenue elasticities corrected for policy changes in the EU", European Commission Discussion Paper Series 018

34. Musgrave, R. A. (1969), "Fiscal systems", New Haven, CT: Yale University Press.

35. Ndikumana, L., Abderrahim, K. (2010), "Revenue mobilization in African countries: does natural resource endowment matter?", African Development Review, 22(3), 351-365.

36. Osoro, N. E., Leuthold, J. (1994), "Changing tax elasticities over time: The case of Tanzania”, African Development Review, 6(1), 31-40.

37. Osoro, N.E. (1995), "Tax reforms in Tanzania: Motivations, directions and implications". African Economic Research Consortium Research Paper No. 38.

38. Pesaran, M. H., Smith, R. P. (1995), "Estimating long-run relationship from dynamic heterogeneous panels", Journal of Econometrics, 68, 79-113.

39. Pesaran, M. H. (2007), "A simple panel unit root test in the presence of cross section dependence", Journal of Applied Econometrics, 22(2), 265-312.

40. Pesaran, M. H., Shin, Y., Smith, R. P. (1999), "Pooled mean group estimation of dynamic heterogeneous panels", Journal of American Statistical Association, 94, 31-54.

41. Shaikh, S. (2012), "Estimating the federal direct tax buoyancy for Pakistan in Post-1973 Era", MPRA Archive Paper 42498.

42. Shome, P. (1988), "On the elasticity of developing country tax systems", Economic and Political Weekly, 23(34), 1750-1754.

43. Singh, T. (2012), "Testing Nonlinearities in Economic Growth in the OECD Countries: An Evidence from SETAR and STAR Models", Applied Economics, 44(30), 3887-3908.

44. Singh, T. (2014), "On the Regime-Switching and Asymmetric Dynamics of Economic Growth in the OECD Countries", Research in Economics, 68(2), 169-192.

45. Skeete, R., Coppin, K., Boamah, D. (2003), "Elasticities and Buoyancies of the Barbados Tax System, 1977 - 1999”, Central Bank of Barbados.

46. Thac, C., Lim, D. (1984), "Papua New Guinea's Tax Performance, 1965-1977”, World Development, 12(4), 451-459.

47. Timsina, N. (2007), "Tax elasticity and buoyancy in Nepal: a revisit”, NRB Economic Review, 19, 921

48. Twerefou D. F., Fumey A., Osei-Assibey E, Asmah E.E. (2010), "Buoyancy and Elasticity of Tax: Evidence from Ghana", West Africa Journal of Monetary Economics, 10(2), 36-70.

49. Twerefou, D.K., A. Fumey, E.O. Assibey, E.K. Asmah (2012), "Buoyancy and elasticity of tax: Evidence from Ghana", Journal of Monetary and Economic Interpretation, 10(2), 122-131. 
50. Upender, M. (2008), "Degree of tax buoyancy in India: an empirical study", International Journal of Applied Econometrics and Quantitative Studies, 5(2).

51. Yousuf, M., Huq, S. (2012), "Elasticity and Buoyancy of major tax categories: evidence from Bangladesh and its policy implication", Research Study Series of the Macroeconomic Wing of the Ministry of Finance, No. - FDRS 03/2013 


\section{APPENDIX}

\section{List of countries}

(in parenthesis start and end date of tax revenue data)

Japan (1980-2017), Australia (1980-2017), New Zealand (1980-2017), Bangladesh (1984-2017), Bhutan (1983-2017), Brunei Darussalam (1990-2017), Myanmar (1980-2017), Cambodia (19942017), Sri Lanka (1980-2017), India (1980-2017), Indonesia (1980-2017), Laos (1990-2017), Malaysia (1980-2017), Maldives (1980-2017), Nepal (1980-2017), Pakistan (1980-2017), Philippines (1987-2017), Singapore (1980-2017), Thailand (1980-2017), Vietnam (1980-2017), Solomon Islands (1981-2017), Fiji (1980-2017), Kiribati (1980-2017), Vanuatu (1981-2017), Papua New Guinea (1983-2017), Tonga (1981-2017), Marshall Islands (1986-2017), Micronesia (1989-2017), Tuvalu (2006-2014), Mongolia (1986-2017)

Table A1. Summary Statistics

\begin{tabular}{l|ccccc}
\hline Variable & Observations & Mean & Standard deviation & Minimum & Maximum \\
\hline Tax revenues & 991 & 15.61 & 6.83 & 1.91 & 37.57 \\
PIT & 666 & 3.43 & 4.28 & 0 & 21.52 \\
CIT & 656 & 3.37 & 3.61 & 0 & 32.05 \\
Tax Goods and Services & 761 & 5.62 & 2.96 & 0 & 13.88 \\
Trade Taxes & 780 & 2.90 & 2.76 & 0 & 14.45 \\
Growth real GDP & 1380 & 4.30 & 4.22 & -15.43 & 36.53 \\
Inflation (deflator based) & 1377 & 8.42 & 23.14 & -37.92 & 487.17 \\
PIT rate & 816 & 32.7 & 3.81 & 26.91 & 39.24 \\
CIT rate & 816 & 29.8 & 3.75 & 23.90 & 37.13 \\
VAT rate & 714 & 16.00 & 0.18 & 15.67 & 16.44 \\
Hamilton Output Gap (\% potential) & 1350 & -0.01 & 0.48 & -15.86 & 4.99 \\
\hline
\end{tabular}


Table A2. PIT Buoyancy in Asian-Pacific Countries, 1980-2017

\begin{tabular}{|c|c|c|c|}
\hline Country & Long run buoyancy & Short run buoyancy & Speed of Adjustment \\
\hline Japan & $0.868 * * *$ & $2.241 * * *$ & $-0.256 * * *$ \\
\hline Australia & $0.911 * * *$ & $1.017 * * *$ & $-0.265 * *$ \\
\hline New Zealand & $0.764 * * *$ & $1.270 * * *$ & $-0.361 * * *$ \\
\hline Bangladesh & $0.881 * * *$ & $8.560 * *$ & $-0.562 * * *$ \\
\hline Bhutan & $1.145^{* * *}$ & 1.949 & $-0.376^{* *}$ \\
\hline \multicolumn{4}{|l|}{ Brunei Darussalam } \\
\hline Myanmar & 5.219 & $4.626 * * *$ & -0.089 \\
\hline Cambodia & $2.301 * * *$ & 1.059 & $-0.571 * * *$ \\
\hline Sri Lanka & $0.771 * * *$ & $1.146^{*}$ & $-0.325 * * *$ \\
\hline India & $1.270 * * *$ & $1.467 * * *$ & $-0.557 * * *$ \\
\hline \multicolumn{4}{|l|}{ Indonesia } \\
\hline Laos & $1.270 * * *$ & $1.580 * * *$ & $-0.553 * * *$ \\
\hline Malaysia & $0.878 * * *$ & -0.201 & -0.382 \\
\hline \multicolumn{4}{|l|}{ Maldives } \\
\hline Nepal & $1.032 * * *$ & 1.107 & $-0.467 * * *$ \\
\hline Pakistan & $1.059 * * *$ & $0.410 * * *$ & -0.320 \\
\hline Philippines & $1.122 * * *$ & $2.825 * * *$ & $-0.382 * * *$ \\
\hline Singapore & $1.626 * * *$ & $3.590 * * *$ & $-2.425 * * *$ \\
\hline Thailand & $1.047 * * *$ & $0.704 *$ & $-0.356 * * *$ \\
\hline Vietnam & $1.452 * * *$ & 0.648 & $-0.466 * *$ \\
\hline Solomon Islands & $1.470 * * *$ & $1.492 * * *$ & $-0.353 * *$ \\
\hline Fiji & $0 . .402 * *$ & 0.308 & $-0.446^{*}$ \\
\hline Kiribati & 0.053 & 1.456 & $-0.730 * *$ \\
\hline Vanuatu & & & \\
\hline Papua New Guinea & $1.209 * * *$ & 0.028 & $-0.222 *$ \\
\hline Tonga & & & \\
\hline Marshall Islands & $1.239 * * *$ & -0.489 & $-1.060 *$ \\
\hline Micronesia & 1.176 & 0.329 & -0.185 \\
\hline Tuvalu & -0.566 & -1.722 & $-1.901 * * *$ \\
\hline Mongolia & $1.163 * * *$ & $0.891 * * *$ & -0.263 \\
\hline
\end{tabular}

Note: Estimation of Equation (10) by MG estimator (see main text for details). Bold italic means statistically greater than one at 5 percent level; bold means statistically not different from one at 5 percent level. Standard errors in parenthesis. *, **, *** denote statistical significance at the 10,5 and 1 percent levels, respectively. 


\section{Table A3. CIT Buoyancy in Asian-Pacific Countries, 1980-2017}

\begin{tabular}{|c|c|c|c|}
\hline Country & Long run buoyancy & Short run buoyancy & Speed of Adjustment \\
\hline Japan & $1.120 * * *$ & $5.438 * * *$ & $-0.472 * * *$ \\
\hline Australia & $1.405 * * *$ & $2.164 * * *$ & $-0.274 * *$ \\
\hline New Zealand & $1.422 * * *$ & $2.413 * * *$ & $-0.555 * * *$ \\
\hline Bangladesh & $1.996 * * *$ & 1.366 & $-0.509 *$ \\
\hline Bhutan & $1.467 * * *$ & 2.016 & $-0.278 * *$ \\
\hline Brunei Darussalam & $1.701 * * *$ & $2.196 * * *$ & $-0.803 * * *$ \\
\hline Myanmar & & & \\
\hline Cambodia & $1.934 * * *$ & 1.357 & $-0.513^{* *}$ \\
\hline Sri Lanka & $0.951 * * *$ & 0.980 & $-0.411 * * *$ \\
\hline India & $1.586 * * *$ & $1.674 * *$ & -0.098 \\
\hline Indonesia & & & \\
\hline Laos & $1.235^{* * *}$ & $1.055 * * *$ & $-0.293 *$ \\
\hline Malaysia & $0.831 * * *$ & $-0.800^{*}$ & $-0.487 * * *$ \\
\hline Maldives & $1.554 * * *$ & 0.344 & -0.108 \\
\hline Nepal & $1.779 * * *$ & -0.467 & $-0.266 * * *$ \\
\hline Pakistan & & & \\
\hline Philippines & $1.278 * * *$ & $1.762 * *$ & $-0.646^{* * *}$ \\
\hline Singapore & 1.261 & 4.174 & -1.069 \\
\hline Thailand & $1.587 * * *$ & $3.068 * * *$ & $-0.293 * * *$ \\
\hline Vietnam & 0.284 & 0.864 & -0.065 \\
\hline Solomon Islands & $1.540 * * *$ & $2.861 * * *$ & $-0.363 *$ \\
\hline Fiji & $1.066 * * *$ & -0.622 & $-0.626 * * *$ \\
\hline Kiribati & -0.474 & -2.415 & -0.554 \\
\hline Vanuatu & & & \\
\hline Papua New Guinea & $1.600 * * *$ & $0.851 *$ & -0.144 \\
\hline Tonga & & & \\
\hline Marshall Islands & $1.131 * * *$ & 5.815 & -2.349 \\
\hline Micronesia & $1.923 * * *$ & -0.118 & $-0.746 * * *$ \\
\hline Tuvalu & $4.690 *$ & $9.820 * * *$ & $-1.357 * * *$ \\
\hline Mongolia & $0.997 * * *$ & $2.270 * * *$ & $-0.716 * * *$ \\
\hline
\end{tabular}

Note: Estimation of Equation (10) by MG estimator (see main text for details). Bold italic means statistically greater than one at 5 percent level; bold means statistically not different from one at 5 percent level. Standard errors in parenthesis. *, **, *** denote statistical significance at the 10,5 and 1 percent levels, respectively. 
Table A4. TGS Buoyancy in Asian-Pacific Countries, 1980-2017

\begin{tabular}{|c|c|c|c|}
\hline Country & Long run buoyancy & Short run buoyancy & Speed of Adjustment \\
\hline Japan & 0.995 & $0.712 * *$ & -0.035 \\
\hline Australia & $0.725 * *$ & 0.348 & -0.111 \\
\hline New Zealand & $1.086^{* * *}$ & $1.134 * * *$ & $-0.192 *$ \\
\hline Bangladesh & $1.119 * * *$ & 1.784 & -0.414 \\
\hline Bhutan & $1.109 * * *$ & 1.703 & $-0.602 * * *$ \\
\hline Brunei Darussalam & $0.704 * * *$ & $0.311 *$ & $-0.877 * * *$ \\
\hline Myanmar & 1.622 & -2.516 & -0.260 \\
\hline Cambodia & $1.625 * * *$ & $1.811 * * *$ & $-0.795 * * *$ \\
\hline Sri Lanka & $0.913 * * *$ & $0.650 * *$ & $-0.183 * * *$ \\
\hline India & $0.967 * * *$ & $0.741 * * *$ & -0.191 \\
\hline Indonesia & $0.741 * * *$ & 0.341 & $-0.761 * * *$ \\
\hline Laos & $1.354 * * *$ & $1.164 * * *$ & -0.434 \\
\hline Malaysia & $1.007 * * *$ & 0.958 & -0.238 \\
\hline Maldives & $0.976 * * *$ & $1.144 * *$ & $-0.223 * * *$ \\
\hline Nepal & -0.285 & $1.164 * * *$ & 0.013 \\
\hline Pakistan & $1.680 * * *$ & $0.995 * *$ & $-1.074 * * *$ \\
\hline Philippines & $0.935 * * *$ & 0.486 & $-0.373 * *$ \\
\hline Singapore & $1.045 * * *$ & $1.489 * * *$ & $-0.592 * * *$ \\
\hline Thailand & $1.075 * * *$ & $1.269 * * *$ & $-0.462 * * *$ \\
\hline Vietnam & $0.992 * * *$ & $1.638 * * *$ & $-0.702 * * *$ \\
\hline Solomon Islands & $1.807 * * *$ & $1.516^{*}$ & $-0.469 * * *$ \\
\hline Fiji & $1.382 * * *$ & $2.399 * * *$ & $-0.390 * * *$ \\
\hline Kiribati & & & \\
\hline Vanuatu & $1.578 * * *$ & $0.891 * *$ & $-0.359 * * *$ \\
\hline Papua New Guinea & $1.576 * * *$ & 0.212 & $-0.408 * * *$ \\
\hline Tonga & $2.857 * * *$ & 1.013 & $-0.416 * *$ \\
\hline Marshall Islands & 4.304 & $1.525^{*}$ & -0.262 \\
\hline Micronesia & & & \\
\hline Tuvalu & 8.726 & 0.564 & -0.499 \\
\hline Mongolia & $1.061 * * *$ & $0.824 * * *$ & $-0.248^{*}$ \\
\hline
\end{tabular}

Note: Estimation of Equation (10) by MG estimator (see main text for details). Bold italic means statistically greater than one at 5 percent level; bold means statistically not different from one at 5 percent level. Standard errors in parenthesis. *, **, *** denote statistical significance at the 10,5 and 1 percent levels, respectively. 


\section{Table A5. Trade Taxes Buoyancy in Asian-Pacific Countries, 1980-2017}

\begin{tabular}{|c|c|c|c|}
\hline Country & Long run buoyancy & Short run buoyancy & Speed of Adjustment \\
\hline Japan & $0.769 * * *$ & $2.084 * * *$ & $-0.395 * * *$ \\
\hline Australia & 2.801 & 0.817 & -0.016 \\
\hline New Zealand & $0.952 * * *$ & 1.099 & $-0.248 * *$ \\
\hline Bangladesh & $0.879 * * *$ & 1.829 & -0.442 \\
\hline Bhutan & $1.060 * * *$ & -2.543 & $-0.344 * * *$ \\
\hline Brunei Darussalam & $0.197 *$ & -0.225 & $-1.013 * * *$ \\
\hline Myanmar & $0.429 * *$ & $-12.602 * *$ & $-1.269 * * *$ \\
\hline Cambodia & $0.944 * * *$ & $1.554 * *$ & $-0.327 * *$ \\
\hline Sri Lanka & $0.954 * * *$ & $1.287 * *$ & -0.141 \\
\hline India & $0.766^{* * *}$ & $2.449 * * *$ & $-0.316^{* * *}$ \\
\hline Indonesia & 0.551 & $2.097 *$ & -0.571 \\
\hline Laos & $1.023 * * *$ & $0.708 * * *$ & $-0.844 * * *$ \\
\hline Malaysia & 0.023 & $2.026 * * *$ & $-0.371 * *$ \\
\hline Maldives & $0.852 * * *$ & $1.103 * * *$ & $-0.204 * * *$ \\
\hline Nepal & $1.101 * * * *$ & $0.856 * *$ & $-0.321 * *$ \\
\hline Pakistan & $1.447 * * *$ & $1.645 * * *$ & $-1.039 * * *$ \\
\hline Philippines & $0.913 * * *$ & 0.720 & $-0.249 * *$ \\
\hline Singapore & -1.409 & 1.427 & -0.186 \\
\hline Thailand & $0.537 * * *$ & $2.627 * * *$ & $-0.197 * * *$ \\
\hline Vietnam & $0.594 * * *$ & -0.318 & $-0.384 * * *$ \\
\hline Solomon Islands & $0.703 * * *$ & 1.062 & $-0.223 *$ \\
\hline Fiji & $1.225 * * *$ & $1.302 * * *$ & $-0.222 * *$ \\
\hline Kiribati & $-0.441 * * *$ & $0.996 * *$ & $-1.03 * * *$ \\
\hline Vanuatu & 0.049 & $1.542 * * *$ & -0.142 \\
\hline Papua New Guinea & $0.307 * *$ & 1.098 & $-0.284 *$ \\
\hline Tonga & 0.164 & 0.551 & -0.116 \\
\hline Marshall Islands & 1.402 & 1.034 & -0.365 \\
\hline Micronesia & & & \\
\hline Tuvalu & $-4.140 * * *$ & $6.763 * * *$ & 0.696 \\
\hline Mongolia & $1.180 * * *$ & $1.863 * * *$ & $-0.589 * * *$ \\
\hline
\end{tabular}

Note: Estimation of Equation (10) by MG estimator (see main text for details). Bold italic means statistically greater than one at 5 percent level; bold means statistically not different from one at 5 percent level. Standard errors in parenthesis. *, **, *** denote statistical significance at the 10,5 and 1 percent levels, respectively. 


\section{Figure A1. Tax Revenues (\% GDP) per country over time, 1980-2017}
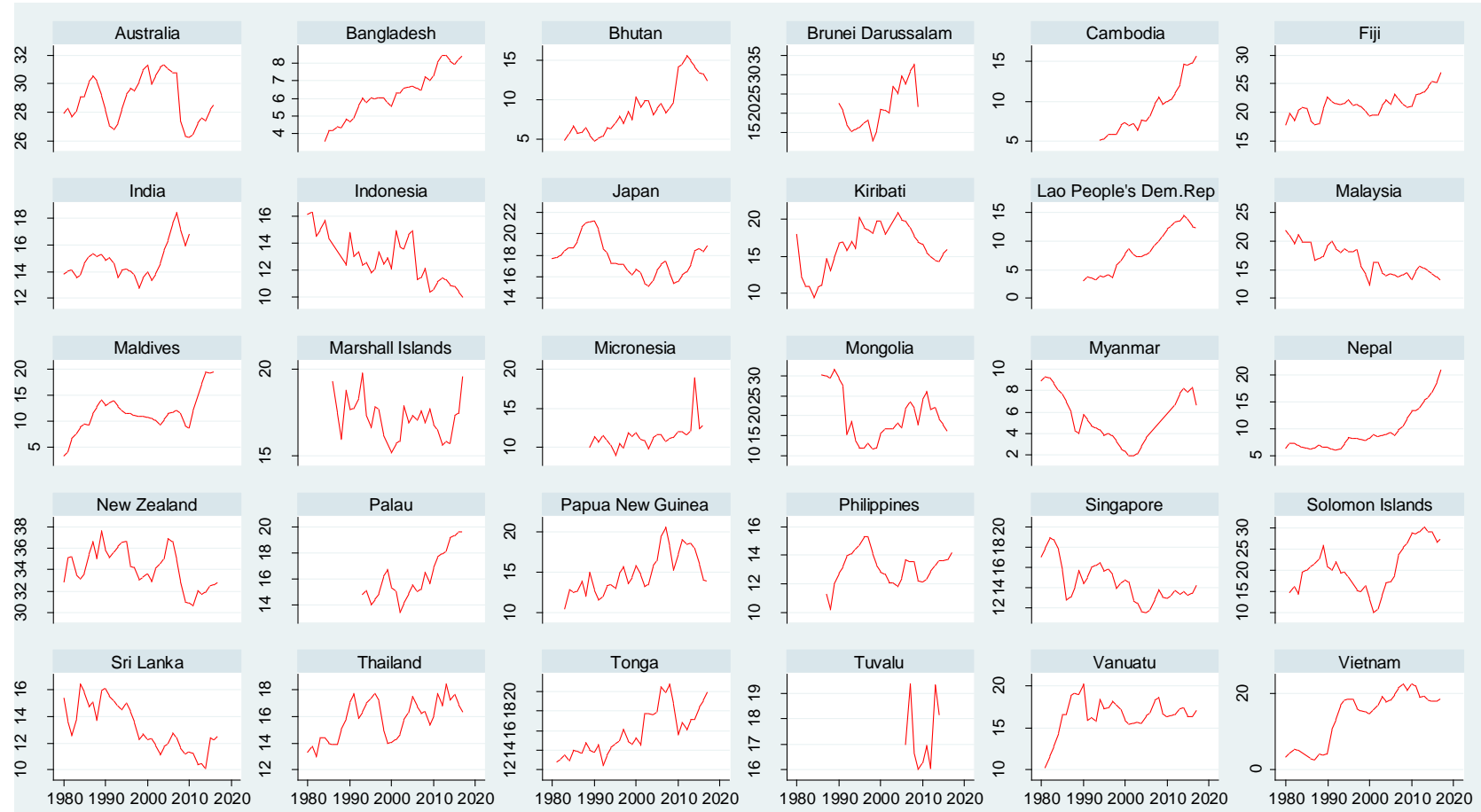

year 